\title{
UTICAJ SUPSTITUCIONE TERAPIJE BUPRENORFINOM
}

Influence of buprenorphine replacement therapy

Milena Despotovicí, Mile Despotović2, Hristos Aleksopulos², Jelena Aleksandrić, Nela Marinovic²

Fakultet medicinskih nauka, Univerziteta u Kragujevcu, ${ }^{2}$ Visoka medicinska škola strukovnih studija Cuprija

APSTRAKT

Uvod. Opijati i opoidi stvaraju i fizičku i psihičku zavisnost. Broj zavisnika od psihoaktivnih supstanci, kao ni zvanični podaci o broju zavisnika od opijata u Srbiji nisu poznati. Kancelarija Ujedinjenih Nacija za drogu i kriminal procenjuje da je, u 2014. godini, oko 29 miliona liudi na svetu zavisno od neke vrste droga. Metod rada. Ovaj rad pripada grupi preglednih radova. Na osnovu ključnih reči (buprenorfin, substituciona terapija, psihoaktivne supstance) pregledane su različite baze podataka, izdvojene reference analizirane, sistematizovane $i$ prikazane u ovom radu. Diskusija. U lečenju zavisnosti od opijata, najčešće se primenjuje supstituciona terapija. Supstituciona terapija kod opoidnih bolesti zavisnosti predstavlja vid terapije u kojoj se koristi antagonist, odnosno nova supstanca sa svojstvima i dejstvima sličnim supstanci koja se obično koristi. Agonisti se koriste u cilju obezbedivanja kontrolisanijeg oblika zavisnosti.

Najesesce korisceni antagonist je metadon cija upotreba u Evropi dostiže 90\% ukupne opoidne supstitucije, mada ga u poslednje vreme sve više zamenjuje buprenorfin, koji je parcijlni agonist-antagonist i najviše se primenjuje u Francuskoj. Istraživanja pokazuju da buprenorfin izaziva manje fizicke zavisnosti u odnosu na metadon i druge supstitute. Takode, cini se da kod buprenorfina postoji manje potencijala za zloupotrebu leka. Zakljucak. Mnogi aspekti uticaja buprenorfina nisu do kraja ispitani. Socijalna reintegracija je važan aspekt socijalne i kao faktori rizika. Kako uticaj buprenorfina na ishode socijalne rehabilitacije do sada nije proučavan, neophodno je dizajnirati nove studije koje bi išle u ovom pravcu.

Ključne reči: buprenorfin, substituciona terapija, psihoaktivne supstance

\section{ABSTRACT}

Introduction. Opiates and opoids create physical and psychological addiction. Official statistics on the number of opiate addicts in Serbia doesn't exist. The United Nations Office on Drugs and Crime estimates that in 2014 some 29 million people in the world are dependent on some sort of drug. Method. This paper belongs to a group of review papers. Based on the key words (buprenorphine, substitution therapy, psychoactive substances), as well as various databases, isolated references were analyzed, systematized and presented in this paper. Discusion. Substitution therapy is most often used therapy method. Substitution therapy is a form of therapy in which an antagonist, a new substance with properties and actions of similar substances, is used. Agonists are used to provide a more controlled form of addiction. The most commonly used antagonist is methadone whose use in Europe reaches 90\% of total opioid substitution, although it has been lately replaced by buprenorphine, a partial agonist-antagonist and is most commonly used in France. Researches show that buprenorphine causes less physical dependence than methadone and other substitutes. It also appears that there is less potential for drug abuse when buprenorphine ad of methadone.

Conclusion. Many aspects of the effects of buprenorphine have not been fully tested. Social reintegration is an important aspect of social rehabilitation of opioid addicts, and it is therefore extremely important to recognize psychological and social factors that can act as protective necessary to design new studies that would go in this direction.

Key words: buprenorphine, substitutional therapy, psychoactive substances

D

vstvenih problema (ICD - 10) definišes sindrom zavisnost
kao skup fizioloških, bihejvioralnih i kognitivnih pojava kome upotreba jedne određene supstance ili skupa supstanci dobija mnogo vecu vrednost za datog pojedinca u odnosu na druge oblike ponašanja koje su nekada imali mnogo veću vrednost. Centralna karakteristika sindroma zavisnosti je želja (1).

Nacionalno istraživanje o stilovima života iz 2014. godine pokazalo je da se upotreba psihoaktivnih supstanci prema mišljenju stanovništva u Srbiji ne smatra najznačajnijim problemom u društvu (upotreba droga se nalazi na šestom mestu). Ipak, u

Korespondent:

Mespotovicm12@gmail.com
Čisti sintetički opijati kao što je metadon nazivaju se opoidima. Neki od neželjenih efekata upotrebe ovih supstanci su: gubitak telesne mase, usporenost, pospanost, uske zenice, izrazito bledilo lica, nerazgovetan govor, vidljivi tragovi uboda iglom zapušten iz gled, sużavanje interesovanja, ceste pozajmice, promena karaktek-
tera, nagle promene raspoloženja, bolovi, preznojavanje, drhtavica, mučnina, prolivi, uznemirenost, gubitak libida, neredovan menmučnina, prolivi, uznemirenost, gubitak libida, neredovan men-
strualni ciklus ili izostanak menstruacije, toksično oštećenje jetre (hepatitis), infekcija virusom HIV-a, depresije, pokušaji samoubistva, kao i realizovana samoubistva. Ukoliko dođe do intoksikacije, va, kao i realizovana samoubistva. Ukoliko dođe do intoksikacije,
odnosno predoziranja, postoji rizik od smrtnog ishoda(3,4). Zbog odnosno predoziranja, postoji rizik od smrtnog ishoda( $(3,4)$. Zbog
ovako ozbiljnih posledica, može se zaključiti da opijum i njegovi derivati izuzetno negativno utiču na psihičcko i fizičko zdravlje zavisnika. Takođe, upotreba ovih psihoaktivnih supstanci jedan je od najvažnijih javnozdravstvenih problema i socijalnih bolesti.

Nažalost, broj zavisnika od psihoaktivnih supstanci, kao ni Kancelarija Ujedinjenih nacija za drogu i kriminal procenjuje da je, u 2014. godini, oko 29 miliona ljudi na svetu zavisno od neke vrste droga. Zavisnici od opijata su grupa koja u najvećoj meri traži da bude uključena u programe terapije u Evropi i Aziji. Prevalenca j zavisnosti od opijata na globalnom nivou iznosi $0,3-0,5 \%$, kada je u pitanju odraslo stanovništvo starosti između 15 i 64 godine stabilna je tokom godina (5)

\section{Metod rada}

Ovaj rad pripada grupi preglednih radova. $\mathrm{Na}$ osnovu $\mathrm{k}-$ jučnih reči (buprenorfin, substituciona terapija, psihoaktivne sup stance) pregledane su različite baze podataka, kako elektronske, i prikazane u ovom rad

\section{Diskusija}

U lečenju zavisnosti od opijata, najčěšće se primenjuje sup stituciona terapija. terapije nije jedini, tako da se u lecenju mogu koristiti razni vidovi psihosocijalnih intervencija, poput individualne i grupne psihoterapije i socioterapije, zatim radna terapija i drugi vidovi terapijskih zajednica (6). Ipak, svi ovi vidovi terapija najcešsce samo dopunjavaju supstitucionalnu terapiju i poboljšavaju njen ishod.

Pre sprovođenja terapije, najbitnije je sagledati potrebe pacijen
sačiniti individualni plan terapije u cilju njegovog izlečenja.

Supstituciona terapija kod opoidnih bolesti zavisnosti predstavlja vid terapije u kojoj se koristi antagonist, odnosno nova supstanca sa svojstvima i dejstvima slicnim psihoaktivnoj supstanci koja se koristi. Agonisti se koriste u cilju obezbeđivanja kontrolisanijeg oblika zavisnosti. Upotreba antagonista ublažav mnoge apstinencijalne simptome, koje osobe zavisne od različiti psihoaktivnili supstanci cesto doživjavaju i smanjuje zdravstvene društvene rizike. Najcesce korišsceni antagonist je metadon čija up otreba u Evropi dostiže 90\% ukupne opoidne supstitucije, mada ga u poslednje vreme sve vise zamenjuje buprenorfin koji je parcijln agonist-antagonist i najviše se primenjuje u Francuskoj. Procenjeno je da je 2000. godine oko 80000 ljudi u Francuskoj bilo na terapiji buprenorfinom, nasuprot 5000 metadonskih pacijenata. Ovaj odnos se tokom godina menjao u korist buprenorfina $(6,7)$. Buprenorfin je otkriven 1966. godine u Engleskoj, u laboratoriji kompanije Rekit i Kolman Razmatranje o upotrebi buprenor-
fina u lečenju bolesti zavisnosti počinje 1975. godine, kada Jasinski fina u lečenju bolesti zavisnosti počinje 1975. godine, kada Jasinsk
izjavljuje da buprenorfin uspešno kombinuje karakteristike metadona sa karakteristikama čistih antagonista opijata i tako blokira samo terapijsko dejstvo kao analgetik malog rizika za zloupotrebu, već i kao novi lek za tretman bolesti zavisnosti, manje toksičan od metadona. Ipak, trebalo je da prođe gotovo tri decenije dok FDA nije odobrila upotrebu buprenorfina u tretmanu opoidne zavisnosti. Do 1985. godine, buprenorfin je bio široko raprostranjen i korišćen kao analgetik. Injekcije buprenorfina bile su odobrene u valne tablete. U Velikoj Britaniji, buprenorfin je od 1978. godine bio korišćen u tretmanu jakih bolova a od 1982. bio je u upotrebi kao sublingvalni analgetik. Nakon mnogo istraživanja i pokušaja da se buprenorfin uključi i programe supstitucionalne terapije, sredinom devedesetih, nakon skandala vezanih za transfuziju krvi, Francuska postaje prva zemlja koja stavlja buprenorfin u upotrebu za lečenje opoidne zavisnosti i dozvoljava lekarima da prepisuju buprenorfin (Subuteks) kao bilo koji lek, u svakodnevnoj lekarskoj praksi (8).

Pored analgezije, promene raspoloženja, euforije, česta je pospanost. Farmakološki efekti se javljaju nakon 15 minuta od unošenja supstance u organizam i traju 6 sati ili duže kada se daju za početalarno. Kada se buprenorfin daje intravenski, vreme a buprenorfina zavisi od PH vrednosti. Dužina vremena držanja tablete pod jezikom ima malo uticaja na apsorpciju. Iako se buprenorfin brzo apsorbuje kroz oralnu sluznicu, sistemska apsorbcia je sporija. Vreme da se postigne najveća koncentracija u plazmi varira od pojedinaca do pojedinca (raspon od 40 minuta do 3.5 sata). Istovremeno uzimanje naloksona ne utiče na farmakokinetiku buprenorfina. Buprenorfin je veoma lipofiličan i ima visoku distribuciju.

ako se o buprenorfinu zna mnogo manje nego o metadonu, koji je i dalje najzastupljeniji lek u supstitucionalnoj terapiji širom sveta, od otkrivanja buprenorfina sprovedene su brojne studije i klinkicki trajali u kojima je testirana delovotvornost i efekti buprenorfina.

Istraživanja su pokazala da su nuspojave koje se javljaju kod nuspojavama metadona i drugih potpunih opoidnim agonista i one ukjjučuju mučnine, povraćanje, vrtoglavice, glavobolje i drugo, ali je njihov intenzitet mnogo manji od upotrebe buprenorfina $(9)$.

Takođe, čini se da kod buprenorfina postoji manje potencijala za zloupotrebu leka. Generalno, zloupotreba supstitucionalne terapije može da bude karakteristika ponašanja opoidnih zavisnika, pri

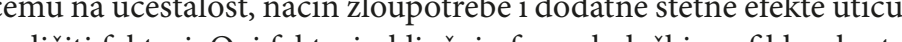
azličiti faktori. Ovi faktori ukjjučuju farmakološki profil konkretnih pojedinaca, supstitut koji koriste, stepen fizicke zavisnosti, individualno iskustvo i ostale faktore. Na zalost, smrt može da bude jedna od ozbiljnih posledica zloupotrebe buprenorfina i ovakav ishod se dešavao širom sveta, najěčšće u kombinaciji sa depresoima centralnog nervnog sistema. Ipak, smrtni slučajevi kao ishod zloupotrebe buprenorfina su daleko malobrojniji u odnosu na smrtne ishode prouzrokovane metadonom. Ono što je bitnije je da izveštaji iz SAD-a i Francuske pokazuju da se broj smrtnih slučajeva, aazvanih zloupotrebom supstitucionog leka, smanjuje (10).

Očigledno je da buprenorfin ima brojne javnozdravstvene efekte. Retrospektivna studija uzastopnih zadesnih predoziranja drogom od juna do oktobra 2013, sprovedena je u Njujorku. Slučajevi sa raspoloživim uzorcima krvi su testirani na buprenorfin i norbuprenorfin korišćcenjem tečne hromatografije sa masenom detekcijom. Rezultati toksikologije su povezani sa dokumentacijom iz njujorške vitalne statistike. Rezultati su pokazali da je od pozitiono $2(2,0 \%)$ bilo poztlivno na metabolite buprenorfina. Svaki od 98 uzoraka pokasmrtnih slučjeva Buprenofin je retko uzrok smring 
nastalih predoziranjem. Kako je bezbednost i efikasnost buprenorfina dobro dokumentovana, a predoziranje kao rezultat tretmana buprenorfinom izuzetno retka pojava, lečenje buprenorfinom se preporučuje (11). Cilj studije sprovedene u Engleskoj i Velsu bio je da se ispita rizik od predoziranja metadonom i buprenorfinom u
tretnamu opoidne zavisnosti. Studija je dizajnirana kao retrospektretnamu opoidne zavisnosti. Studija je dizajnirana kao retrospek-
tivna studija i koristila je nacionalne baze podataka za Englesku Vels. Podaci o smrtnim ishodima čiji je uzrok psihoaktivna sup-
stanca dobijeni su iz Kancelarije za nacionalnu statistiku, a podaci stanca dobijeni su iz Kancelarije za nacionalnu statistiku, a podaci zdravstvene službe za period 2007-2012. Tokom ovog perioda od 6 godina, registrovano je ukupno 2366 smrtnih slučajeva povezanih sa metadonom i 52 slučaja povezanih sa buprenorfinom. Od 2007 do 2012 , smrt usled predoziranja se dešavala u 0.137 na 1000 recepata za metadon, u odnosu na 0.022 na 1000 prepisanih recepata za buprenorfin (uključujucúi buprenorfina-nalokson). Analiza podataka pokazala je odnos relativnog rizika od 6,23 za metadon u odnosu na buprenorfin. Ova analiza relativne bezbednosti buprenorfina i metadona u okviru supstitucione terapije otkriva d je buprenorfin šest puta sigurniji nego metadon i da je rizik od predoziranja mnogo manji (12)

Detoksikacija je jedan od važanijih aspekata lečenja, ali se relativno malo zna o vremenu trajanja i ozbilinosti posledica tokon perioda detoksikacije i skidanja sa buprenorfina. Sekundarna analiza podataka iz randomizovane, kontrolisane placebom, dvostruko slepe studije Duna i saradnika objšnjava ovaj fenomen. Cilj je bio da se utvrdi vremenski tok i težina detoksikacije i skidanja sa buprenorfina pod rigoroznim, dvostruko-slepim uslovima, koristec više kriterijuma za skidanje sa leka. Ucesnici su bili odrasli opoidni zavisnici, podvrgnuti tretmanu buprenorfinom i nasumično su podeljeni u grupe. Grupa kod koje je režim skidanja trajao 4 nedelje doživela je relativno blage i stabilane simptome tokom kursa skidanja, sa nekoliko ekstremih vrhova u teżini simtoma. Nasuprot tome, grupe kod kojim je rezim trajao jednu ili dve nedelje doživele

\section{ZAKLJUČAK}

Postojeća istraživanja govore u prilog tome da buprenorfin u manjoj meri izaziva fizičku zavisnost u odnosu na metadon, iako je metadon i dalje najěěšć koriščena supstanca u substitucionoj terapiji. Međutim, mnogi aspekti uticaja buprenorfina nisu do kraja ispitani. Socijalna reintegracija je važan aspekt socijalne rehabilitacije opoidnih zavisnika i zato je izuzetno značano prepoznati psiho-socijalne faktore koji mogu delovati kao protektivn faktori, ali i kao faktori rizika. Kako uticaj buprenorfina na ishode
socijalne rehabilitacije do sada nije proučavan, neophodno je buprenorfina, a zatim pad nakon toga. Grupa koja je bila na režimu od četiri nedelje imala je manje problema sa snom, u odnosu na druge dve grupe (13)

Istraživanja su pokazala i da je buprenorfin bezbedniji za (14,15), kao i da je seksualna disfunkcija kod terapije buprenorfinom manje zastupljena nego kod erapije metadonom (16). Ipak, i pored brojnih pozitivnih strana buprenorfin može izazvati i neke neželjene efekte, pa je tako dokazano da upotreba buprenorfina može dovesti do nepravilnosti u disanju tokom sna (17).

Relativno mali broj studija bavi se uticajem buprenorfina na socijalno funkcionisanje i socijalnu rehabilitaciju opoidnih zavisnika u režimu supstitucionalne terapije. Socijalni efekti terapie metadonom su češće ispitivani, što je i logično imajući u vidu istoriju i široku zastupljenost leka $(18,19,20)$. Ipak, znajući da su socijalni faktori u stalnoj interakciji sa psihološkim profilom i bioloskim činjenicama, neophodno je utvrditi kakav je efekat buprenorfina na socijalnu integraciju zavisnika. Najzad, socijalno funkcionisanje je jedan od aspekata kvaliteta života i važan faktor avnozdravstvenih strategija, koji može poslužiti kao baza novih Rionalnih i lokalnih planova u rehabilitaciji opoidnih zavisnika. Rezultati dobijeni u studiji sprovedenoj na zdravoj odraslo populaciji, sugerišu da i niske doze buprenorfina smanjuju odgovore na neke vrste negativnih socijalnih stimulusa, dok istovremeno poboljšavaju pozitivno reagovanje na socijalne stimulanse. Ovakvi rezultati obezbeduje podršku za dalja ispitivanja uloge opijata u posrednovanju izmedu reagovanja na socijalno odbijanje i reagovanja na socijalne nagradu (21). Prema nekim podacima, upotreba buprenorfina povecava kvalitet zivota opoidnih zavisnika i ovaj trend je vidljiv u svim aspektima kvaliteta zivota: fizickom, psiholoskom, socijalnom 1 aspektu okruženja (22). Podaci iz franastili da su osobe koje koriste metadon in buprenornh sklone rizičnom ponašanju u saobracaju jem ranjima nesreća, što se može objasniti kombinovanim uticajem ranijeg rizičnog ponašanja i tretmana ovim supstancama (23).

dizajnirati nove studije koje bi išle u ovom pravcu. Takođe, neophodno je prepoznati smer ove interakcije i utvrditi da li socijalni aktori utiču na terapiju buprenorfinom, u kojoj meri i da li buprenorfin utiče na socijalnu rehabilitaciju i reintegraciju pojedinca usistem, vodeci racuna o individualnom psiholoskom profilu svakog uključenog pojedinca. Nažalost, brojni instrumenti za procenu socijalnog funkcionisanja nisu validirani za srpsko govorno
područje, pa je validacija ovih skala neophodna u budućnosti.

\section{LITERATURA}

WHO, Abuse (drug, alcohol, chemical, substance or psychoactive substance), available at:

http://www.who.int/substance_abuse/terminology/abuse/en/

2. Nacionalno istraživanje o stilovima života stanovništva Srbije 2014. godine korišćenje psihoaktivnih supstanci i igre na sré́u Institut za javno zdravlje Srbije „Dr Milan Jovanović Batut”, jun 2014.

3. Milowa zić D Sakaman S, Mićí́ I Dimitrijević I Bolesti zavisnosti. Emropski centar za mir i razvoj (ECPD) Univerziteta za mir Ujedinjenih nacija, 2004

4. Znaci zloupotrebe opijata, available at: http:

//www.draizerova.org.rs/index.php?option=com_contenterview $=$ articleorid $=29 \mathrm{e}$ Itemid $=45$

5. World Drug Report, Executive Summary, available at: http:

Wwww.unodc.org/documents/data-and-analysis/WDR2012/Executive_summary_24may.pdf

6. Vester A, Buning E. Informacija o supstitucionalnoj terapiji za zavisnost od opijata. EuroMehtwork, 2003, available at:

http://putokaz.org.rs/pdf/INFO_O_SUPST_TERAPIJI.pdf

Li X1, Shorter D, Kosten TR. Buprenorphine in the treatment of opioid addiction: opportunities, challenges and strategies. Expert Opin Pharmacother. 2014 Oct;15(15):2263-75.

8. Campbell N, Lovell A. The history of the development of buprenorphineas an addiction therapeutic. Ann N Y Acad Sci.

Washington T, Fanciullo G. Buprenorphine: Side Effects and Tolerability, in Handbook of Methadone Prescribing and Buprenorphine Therapy, pp 201-211, Springer 2013 edition

10. Lofwall M, Walsh S, A Review of Buprenorphine Diversion and Misuse: The Current Evidence Base and Experiences from Around the World. A Addict Med. 2014 Sep-Oct; 8(5):315-26.

1. Paone D1, Tuazon E2, Stajic M3, Sampson B3, Allen B2, Mantha S2, Kunins H2. Buprenorphine infrequently found in fatal overdose in New York City. Drug Alcohol Depend. 2015 Oct 1;155:298-301

2. Marteau D, McDonald R, Patel K. The relative risk of fatal poisoning by methadone or buprenorphine within the wide population of England and Wales. BMJ Open 2015;5:e007629

Dunn KE, Saulsgiver KA, Miller ME, Nuzzo PA, Sigmon SC. Characterizing opioid withdrawal during double-blind Alcohol Depend. 2015 Jun 1;151:47-55.

14. Meyer MC1, Johnston AM, Crocker AM, Heil SH. Methadone and buprenorphine for opioid dependence during pregnancy: a retrospective cohort study. J Addict Med. 2015 Mar-Apr;9(2):81-6

5. Wiegand SL1, Stringer EM, Stuebe AM, Jones H, Seashore C, Thorp J. Buprenorphine and naloxone compared with methadone treatment in pregnancy. Obstet Gynecol. $2015 \mathrm{Feb} ; 125(2): 363-8$.

16. Yee A1, Danaee M1, Loh HS2, Sulaiman AH1, Ng CG1. Sexual Dysfunction in Heroin Dependents: A Comparison between Methadone and BuprenorphineMaintenance Treatment. PLoS One. 2016 Jan 28;11(1):e0147852.

17. DeVido J1, Connery H2, Hill KP2. Sleep-disordered breathing in patients with opioid use disorders in long-term maintenance on buprenorphine-naloxone: A case series. J Opioid Manag. 2015 Jul-Aug;11(4):363-6.

18. Babor T et all. Behavioral and Social Effects of Heroin Self-Administration and Withdrawal. Arch Gen Psychiatry. 1976;33(3):363-367

19. Sun HM, Li XY, Chow EP, Li T, Xian Y, Lu YH, Tian T, Zhuang X, Zhang L. Methadone maintenance treatment programme reduces criminal activity and improves soc

20. Chang KC1,2, Lin CY3. Effects of publicly funded and quality of life on attendance rate among methadone maintenance treatment patients in Taiwan: an 18-month follow-up study. Harm Reduct J. 2015 Oct 16;12:40.

1. Bershad AK1, Jaffe JH2, Childs E1, de Wit H3. Opioid partial agonist buprenorphine dampens responses to psychosocial stress in humans. Psychoneuroendocrinology. 2015 Feb;52:281-8.

22. Mitchell SG1, Gryczynski J, Schwartz RP, Myers CP, O'Grady KE, Olsen YK, Jaffe JH. Changes in Quality of Life following Buprenorphine Treatment: Relationship with Treatment Retention and Illicit Opioid Use.J Psychoactive Drugs. 2015 Apr-Jun;47(2):149-57.

23. Corsenac P1, Lagarde E, Gadegbeku B, Delorme B, Tricotel A, Castot A, Moore N, Philip P, Laumon B, Orriols L. Road traffic crashes and prescribed methadone and buprenorphine: a French registry-based case-control study. Drug Alcohol Depend. 2012 Jun 1;123(1-3):91-7. 